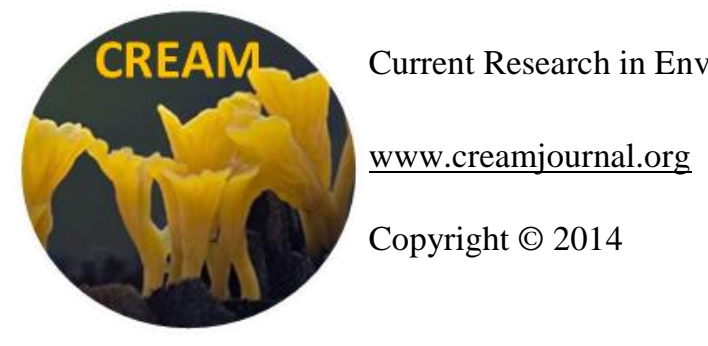

\author{
Article \\ CREAM \\ Online Edition
}

Doi 10.5943/cream/4/1/4

\title{
Effect of environmental and nutritional conditions on phosphatase activity of Aspergillus awamori
}

\section{Jena SK and Rath $\mathrm{CC}^{1^{*}}$}

P. G. Department of Botany, North Orissa University, Baripada, India-757003

${ }^{I}$ Department of Biotechnology, Science and Technology Department, Government of Odisha, Bhubaneswar-751003, India

Jena SK, Rath CC 2014 - Effect of environmental and nutritional conditions on phosphatase activity of Aspergillus awamori and viability test of the strain. Current Research in Environmental \& Applied Mycology 4(1), 45-56, Doi 10.5943/ream/4/1/4

\begin{abstract}
Phosphatase production by Aspergillus awamori (S3-4) was investigated by batch culture. The $\mathrm{pH}$, incubation period, temperature, carbon and nitrogen sources were optimized for maximum enzyme production. Production of acid phosphatase was more in comparison to alkaline phosphatase in all conditions. The optimal $\mathrm{pH}$, incubation period, temperature were reported to be $\mathrm{pH} 6,6$ days and $29^{\circ} \mathrm{C}$ respectively. Maximum enzyme activity was observed at $3 \%$ of sucrose and $0.1 \%$ of ammonium nitrate, in the medium. Molecular characterization of rDNA of ITS region was done for identification and it was identified as Aspergillus awamori, a cryptic species of Aspergillus niger.
\end{abstract}

Keywords - biofertilizers - Cryptic species - ITS1/ITS4

\section{Introduction}

Soil microbial enzymes, including extracellular phosphatase, are important for degrading organic and inorganic substances. Some microorganisms have mineralization and solubilization potential for organic and inorganic phosphorus by extracellular phosphatase (alkaline and acid phosphatase). Phosphorus solubilizing activity is determined by the ability of microbes to release organic acids, or/and proton extrusion which through their hydroxyl and carboxyl groups chelate the cation bound to phosphate, the latter being converted to soluble forms (Surange 1995, Dutton \& Evans 1996, Nahas 1996). Production of different extra cellular organic acids likes citric acid, aspartic acid, glutamic acid, oxalic acid by the microbes results in acidification of its surroundings to solubilise the insoluble phosphate (Deubel et al. 2000, Henri et al. 2008, Khan et al. 2009). Species of bacteria, fungi, yeasts, and actinomycets are capable of solubilizing phosphate in the soil that has been isolated (Illmer \& Schinner 1992, Whitelaw 2000, Abe-Alla 2001, Daimon et al. 2006). Insoluble phosphate is made soluble by strains from bacterial genera Pseudomonas, Bacillus and Rhizobium (Bacillus megaterium, B. circulans, B. subtilis, B. polymyxa, B. sircalmous, Pseudomonas striata, and Enterobacter) along with Penicillium and Aspergillus among fungi (Whitelaw 2000, Vazquez 2000, Khiari \& Parent 2005, Khan et al. 2009). Similipal Biosphere Reserve located in between $21^{\circ} 28^{\prime}$ to $22^{\circ} 08^{\prime} \mathrm{N}$ latitude and $86^{\circ} 04^{\prime}$ to $86^{\circ} 37^{\prime}$ E longitude, Mayurbhanj district of Orissa state in the Indian union and covering $5,578 \mathrm{~km}^{2}$ of forest land and 
represent a unique ecosystem. This virgin ecosystem is not explored in terms of its microbial wealth, hence, an attempt is made through this investigation in search of phosphate solubilising microorganisms in order to exploit their uses as bio fertilizers.

\section{Materials \& methods}

\section{The isolate (S3-4)}

The fungal isolate used in the present study was isolated form rhizospheric soil of Similipal Biosphere Reserve. The isolate S3-4 (Aspergillus sp.) showed phosphatase activity in terms of zones of clearance on Pikovaskay's agar (Yeast extract $0.500 \mathrm{gm} / \mathrm{L}$, Dextrose $10 \mathrm{gm} / \mathrm{L}$, Calcium phosphate $5 \mathrm{gm} / \mathrm{L}$, Ammonium sulphate $0.5 \mathrm{gm} / \mathrm{L}$, Potassium chloride $0.2 \mathrm{gm} / \mathrm{L}$, Magnesium sulphate $0.1 \mathrm{gm} / \mathrm{L}$, Manganese sulphate $0.0001 \mathrm{gm} / \mathrm{L}$, Ferrous sulphate $0.0001 \mathrm{gm} / \mathrm{L}$, agar $15 \mathrm{gm} / \mathrm{L}$ ) plate was characterised further.

\section{Identification of the isolate}

The microscopic examination of the isolate was done through Lacto-phenol Cotton Blue staining technique. Further, the molecular characterization was done using DNA sequencing and phylogentic analysis. Genotypic identification was carried out by PCR amplification and partial sequencing of the $18 \mathrm{~S}$ rDNA of ITS region for the strengthening the morphological identification. The rDNA sequence of $18 \mathrm{~S}$ ribosomal RNA gene of ITS region, ITS+26S(D1/D2) and $\beta$-tubulin region were tried to amplify by PCR using (forward ITS1-5'-TCC GTA GGT GAA CCT GCG G3' reverse ITS4-5'-TCC TCC GCT TAT TGAT ATGC-3'), ( forward NL-1 5'-GCA TAT CAA TAA GCG GAG GAA AAG reverse NL-4 primer 5'-GGT CCG TGT TTC AAG ACG G) (forward Bt2a GGT AAC CAA ATC GGT GCT GCT TTC, reverse Bt2b ACC CTC AGT GTA GTG ACC CTT GGC) primers respectively (O’Donnell 1993, Glass \& Donaldson 1995, Bakri et al. 2010). Primers were synthesized and PCR amplifications with subsequent sequencing were carried out by Macrogen Inc., South Korea. A comparative study of rDNA sequences of isolate with other rDNA sequence of Aspergillus sp. was done using BLAST algorithm at the website http://www.ncbi.nlm.nih.gov. Evolutionary analyses were conducted in MEGA5 (Tamura et al. 2011). Total 32 closely related Aspergillus sp with S3-4 were taken in to account for preparation of phylogeny tree by the method of maximum parsimony. The assembled sequence of ITS region of 18S RNA of the isolate was submitted in NCBI.

\section{Assay for phosphatase activity of the isolate}

The isolate (S3-4) was cultured in Pikovaskay's broth, at $28 \pm 2^{0} \mathrm{C}$, for 6 days. After the incubation period, the culture was filtrated by Whatman filter paper. The filtrate was centrifuged at $1000 \mathrm{rpm}$ for $10 \mathrm{~min}$ and the supernatant was used for phosphatase assay, spectrophotometrically using p-nitrophenyl phosphate (p-NPP) as substrate. The p-nitrophenol was used to make standard curve for determination of phosphatase activity. Enzyme activity was indicated by an increase in the absorbance of light at $\lambda=410 \mathrm{~nm}$. Phosphatase activity was transformed to absolute units using a standard curve based on increasing concentrations of p-nitrophenol (Berman et al. 1990). The presence of acid phosphatase and alkaline phosphatase were determined as: $0.4 \mathrm{ml}$ filtrate was incubated for 20 min with $0.8 \mathrm{ml}$ of $\mathrm{p}-\mathrm{NPP}$ at $70^{\circ} \mathrm{C}$ for alkaline phosphatase, adding $0.4 \mathrm{ml}$ of $0.05 \mathrm{M}$ tris-HCL buffer $(\mathrm{pH} 9.5)$ and at $65^{\circ} \mathrm{C}$ for acid phosphatase in $0.25 \mathrm{M}$ sodium acetate buffer (pH 6.0). Reaction was terminated by adding $2 \mathrm{ml}$ of $1 \mathrm{~N}$ of $\mathrm{NaOH}$ to measure the freely dissolved phosphatase activity (acid and alkaline). The activity was expressed in $\mathrm{n}$ mol p-NP released/ml/ min. (Lo' pez et al. 2006).

\section{Dry weight measurement}

The dry weight of the isolate was measured by oven drying at $80^{\circ} \mathrm{C}$ for 20 hours of the filtrated cell mass in all experiments and was compared with enzymatic activity. 


\section{Condition optimization of phosphatase activity of the isolate}

\section{Effect of physical parameters}

Effect of different physical parameters such as incubation period, $\mathrm{pH}$, and incubation temperature on the phosphatase activity of the isolate was studied. The fungal isolate was incubated in Pikovaskay's broth under different conditions i.e $\mathrm{pH}$ (4-10), temperature $\left(20^{\circ} \mathrm{C}, 29^{\circ} \mathrm{C}, 37^{\circ} \mathrm{C}\right.$ and $45^{\circ} \mathrm{C}$ ) and incubation period (2-8days). The phosphate solubilising activity was measured by the procedure described earlier.

\section{Effect of carbon source}

An experiment was designed to study the effect of different carbon sources on phosphatase activity of the isolate. Briefly, Pikovaskay's medium was supplemented with different carbon sources (sucrose, dextrose, starch, manitol, sorbitol and fructose) at varied concentration $(1 \%, 2 \%$, $3 \%$ ) separately. The isolate (S3-4) was incubated in the carbon supplemented medium at $29^{\circ} \mathrm{C}$ for 6 days and the phosphatase activity was studied.

\section{Effect of nitrogen source}

The Pikovaskay's medium was supplemented with different nitrogen sources (Ammonium Nitrate, Ammonium Sulphate, Sodium Nitrate, Calcium Nitrate, Asparargin, Potassium Nitrate and Glycin) with varied concentrations $(0.5 \%, 1 \%, 1.5 \%$ and $2 \%)$ separately. The isolate was incubated at $29^{\circ} \mathrm{C}$ for 6 days and the phosphatase activity was studied.

\section{Effect of organic matters on phosphatase activity of the isolate}

An effort was made to study the effect of organic manures [Mustard cake, Neem cake, Groundnut cake and Colococia (cocoyam)] on phosphatase activity of the isolates. Fifty grams of dry weight of above described cake was mixed with $400 \mathrm{ml}$ distilled water in 1 liter conical flask (organic manure stock solution was prepared to be 12.5\%). Then the mixture was steamed for 15 minutes at $121^{\circ} \mathrm{C}$. Further, the steamed mixture was filtered by a thin cotton cloth, and the filtrate was used as stock. From the stock, $50 \mathrm{ml}$ filtrate was taken and made up to $200 \mathrm{ml}$ with distilled

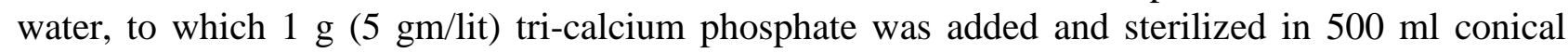
flask. The final concentration of organic manure in medium was 3 to $3.1 \%$. After sterilization the test organism was transferred in to the medium and incubated at $29^{\circ} \mathrm{C}$ for 6 days and the phosphatase activity was determined by the procedure described earlier.

\section{Test for viability of the isolate in the carrier material}

Mustard Cake was observed to be the suitable organic substrate from the previous experiment. Therefore, an experiment was designed to study the viability of the isolate in the soil with different concentrations of mustard cake. Spore suspension of the isolate was made by washing a freshly sporulated potato agar slant of the fungi with sterilised distilled water $\left(4.7 \mathrm{X} 10^{4}\right.$ spores $/ \mathrm{ml})$. Mustard cake at different concentrations $(10 \%, 20 \%, 40 \%$ and $80 \%)$ was mixed with soil (final volume $500 \mathrm{gm}$ ) and was sterilised in 1 litter beaker. Each beaker were inoculated with 1 $\mathrm{ml}$ of spore suspension, mixed well and incubated at $29^{\circ} \mathrm{C}$ for six months. Soil (500gm) without mustard cake served as control. The viability and population of the isolate was determined by standard spread plate count method after 4, 8, 12, 16, 45, 90 and 180 days of incubation.

\section{Results}

\section{Identification of the isolate}

Primarily, the isolate was identified by studying the colony morphology on Czapeckdox agar (CDA) medium and microscopic analysis of reproductive structure. The growth was slow, colony first appeared whitish and later on turned greyish yellow after 3 days of incubation. Colony on CDA was compact, velutinous margin, reveres of the colony was light orange, white to cream 
coloured sclerotia. The sclerotia were spherical to sub-spherical in shape, 1-1.5 mm diameter, with variable conidial heads, radiating divergent coloums. Conidiophores strip up 1 to $1.2 \mathrm{~mm}$ long, light yellow, with thick and echinulate or smooth wall. Vesicles were spherical 18-36 um diameters with smooth walled conidia, finally roughened, spherical 2- 3.5 um (Fig. 1). Based on the above microscopic observations the isolate was tentatively identified and assigned to the genera Aspergillus.

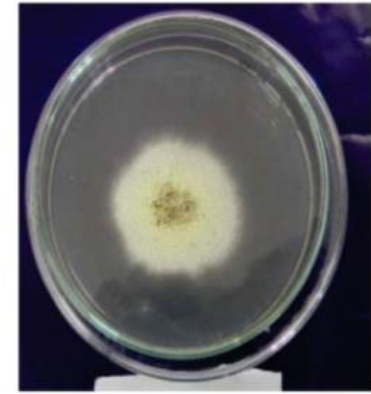

(A)

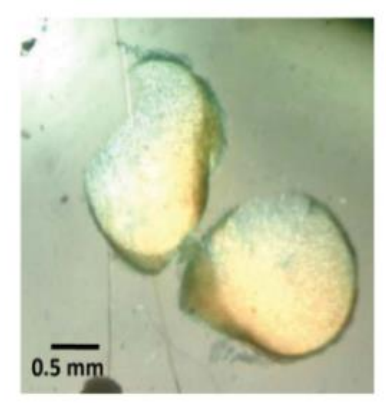

(D)

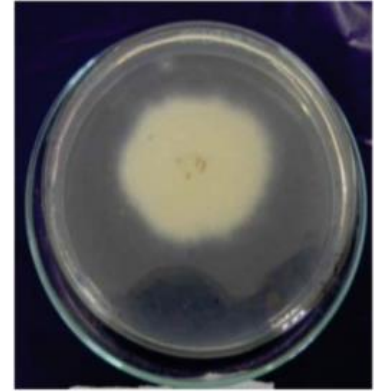

(B)

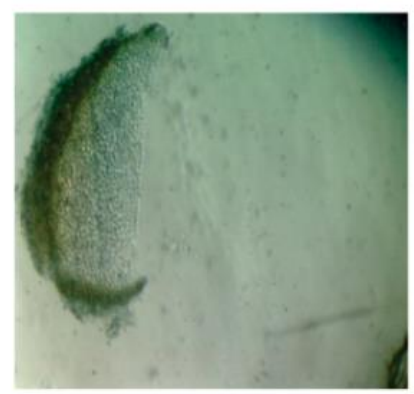

(E)

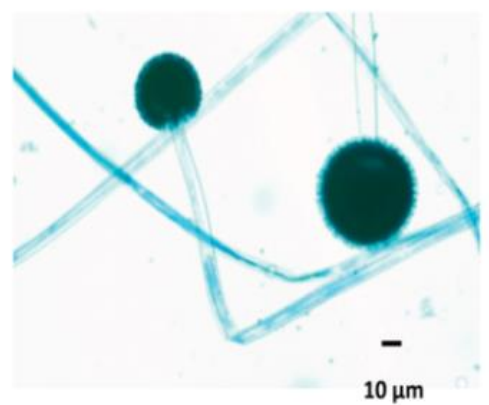

(C)

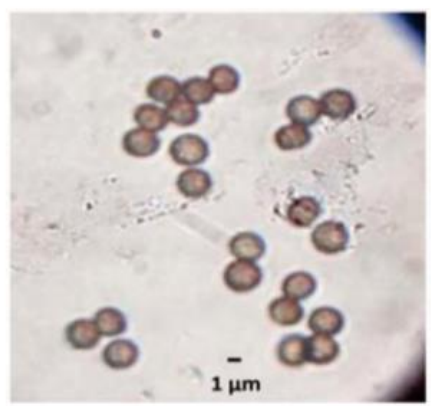

(F)

Fig. 1 - Morphological characters of Aspergillus awamori: A-B, colony morphology; C, conidial head and conidiaphore; D-E sclerotia section; F conidial structure.

PCR amplification with the primers (Bt2a/Bt2b and NL-1/Nl-4) but unfortunately, no bands were observed on a gel. Only positive response was found by primers ITS1/ITS4. Since, fungal ITS sequences generally provide greater taxonomic resolution than sequences generated from coding regions (Anderson et al. 2003), the potent organism with phosphatase activity was identified morphologically as Aspergillus sp., Genomic DNA of the isolate was extracted and ITS rDNA was amplified and sequenced. The sequence data were subjected to BLAST search in NCBI database. Based on BLAST analysis of ITS rDNA sequence, the isolate showed closest homology with Aspergillus awamori. Literature search revealed this species to be cryptic of Aspergillus niger. A molecular phylogeny analysis was carried out along with other 32 closely related Aspergillus species. Phylogenetic tree generated by maximum parsimony showed that the isolate clustered with all the cryptic species of Aspergillus niger with supported bootstrap value of $100 \%$. Tree \#1 out of 24 most parsimonious trees (length $=616$ ) is shown. The consistency index is $(0.556291)$, the retention index is $(0.711621)$, and the composite index is $0.479420(0.395869)$ for all sites. The percentage of replicate trees in which the associated taxa clustered together in the bootstrap test (1000 replicates). The MP tree was obtained using the Close-Neighbour-Interchange algorithm (Nei and Kumar 2000).) with search level 1 in which the initial trees were obtained with the random addition of sequences (10 replicates). The analysis involved 33 nucleotide sequences. There were a total of 1253 positions in the final data set (Fig. 2). The sequence was submitted in the data base of NCBI having no S3-4 KC316117. 


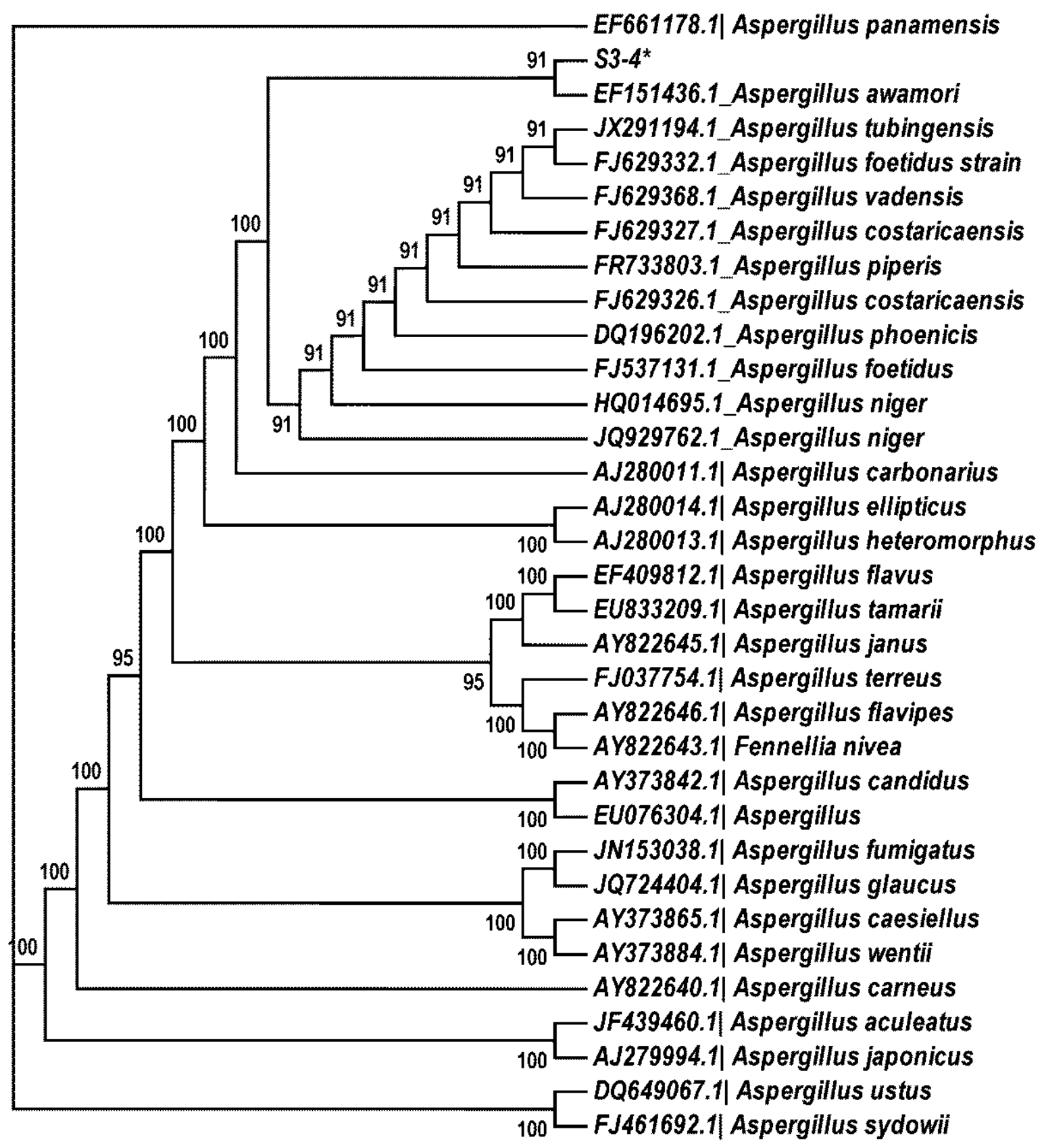

Fig. 2 - Phylogenic tree generated by maximum Parsimony showing evolutionary relationship of Aspergillus sp. (S3-4) along with 32 closely related of Aspergillus sp.

\section{Effect of physical parameters on phosphatase activity}

The phosphatase activity of the isolate was assayed using P-NPP as the substrate following the method of Berman et al. (1990), Lo' pez et al. (2006). While studying the effect of incubation period on phosphate solubilising activity of the isolate (S3-4), it was observed that the isolate showed maximum phosphatase activity after 6 days of incubation at $29^{\circ} \mathrm{C}[25 \pm 1.53$ and $15.68 \pm 0.58$ $\mathrm{n}$ mol p-nitrophenol/ml/20min of acid and alkaline phosphatase respectively (Fig. 3)].Surprisingly, while comparing the dry biomass with respect to phosphatase activity, it was found that no growth of the isolate was observed after five days of incubation. Hence, all experiments were further conducted after 6 days of incubation. On the other hand, the production of alkaline phosphatase was found to be more than acid phosphatase on $2^{\text {nd }}$ and $3^{\text {rd }}$ days of incubation. 


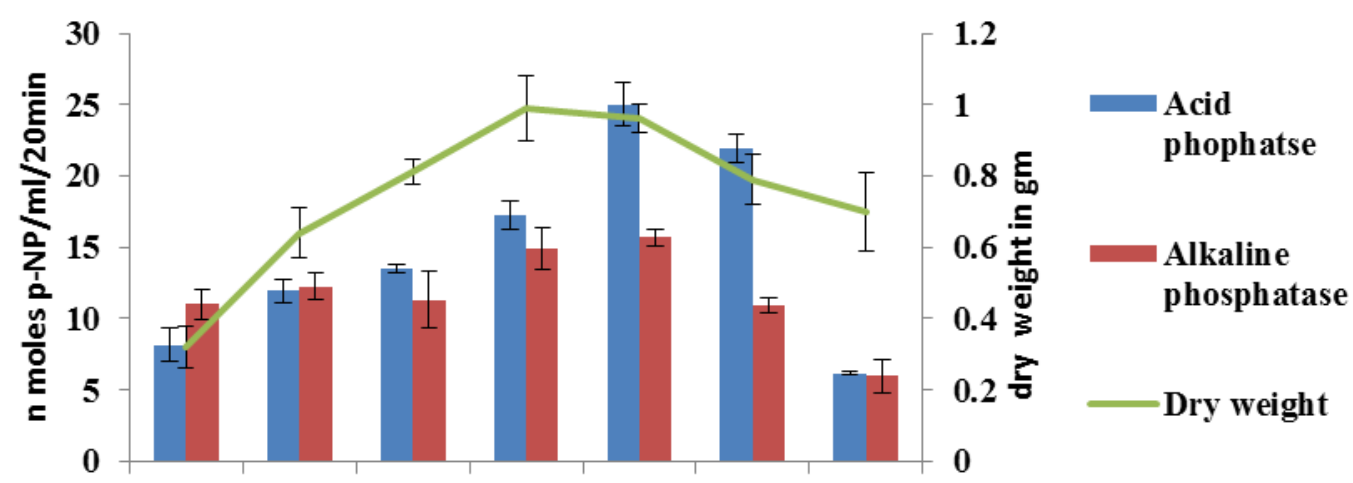

$\mathbf{2}$ days 3 days 4 days 5 days 6 days 7 days 8 days

\section{Incubation period}

Fig. 3 - Effect of Incubation period on phosphatase production

The effect of temperature on phosphatase activity was studied on Pikovaskay's medium by incubating the culture flasks at different temperatures $\left(22^{\circ} \mathrm{C}, 29^{\circ} \mathrm{C}, 37^{\circ} \mathrm{C}\right.$ and $\left.45^{\circ} \mathrm{C}\right)$ after 6 days of incubation. The maximum phosphatase activity was observed to be $26.5 \pm 1.82$ and $14.6 \pm 0.97 \mathrm{n}-$ $\mathrm{mol} \mathrm{p}$-nitrophenol $/ \mathrm{ml} / 20 \mathrm{~min}$ for both acid and alkaline phosphatase respectively, at $29^{0} \mathrm{C}$. A decrease in both alkaline and acid phosphatase was reported at higher temperatures (Fig. 4).

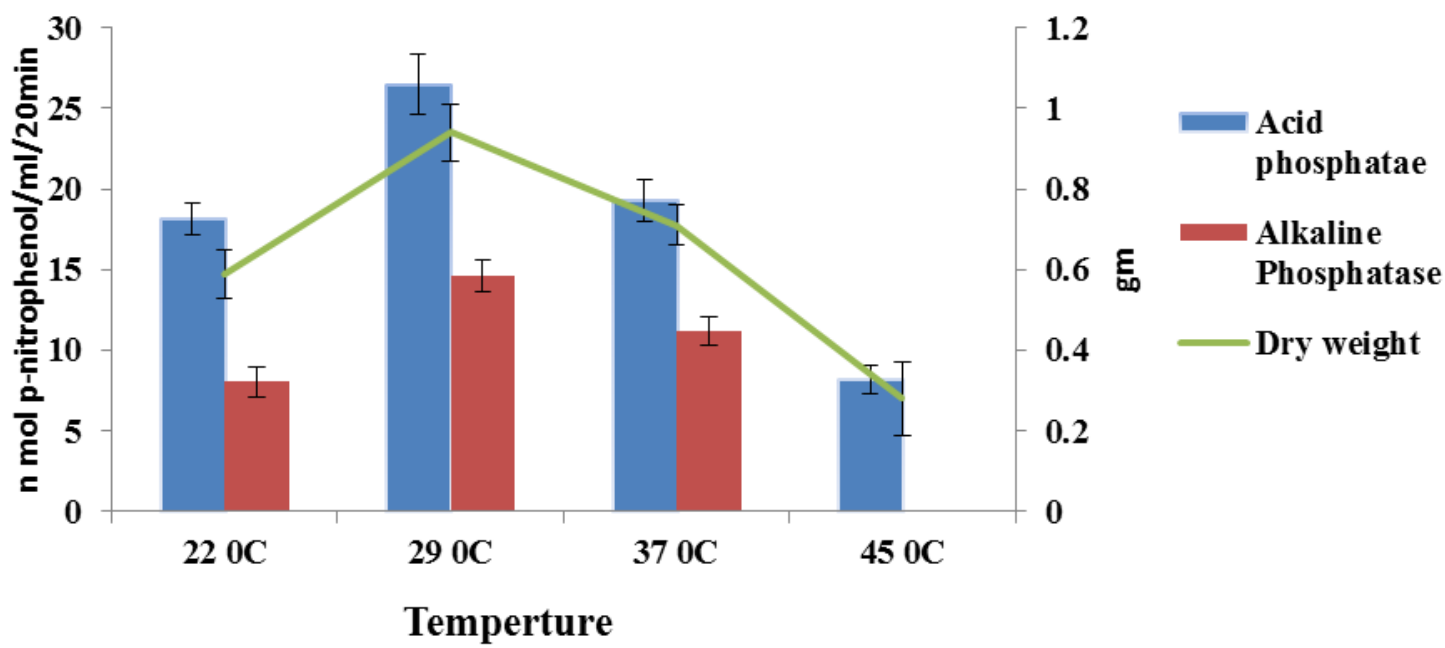

Fig. 4 - Effect of incubation temperature on phosphatase production

When the phosphate solubilizing activity of the isolate was studied at different $\mathrm{pH}(\mathrm{pH} 4-$ $10)$, maximum activity was observed at $\mathrm{pH} 6(28.1 \pm 2.6$ and $20.6 \pm 0.45 \mathrm{n}$ mol pnitrophenol $/ \mathrm{ml} / 20 \mathrm{~min}$ of acid and alkaline phosphatase respectively) and a degree in reduction in activity was recorded at alkaline $\mathrm{pH}$ range (Fig. 5).

\section{Effect of carbon and nitrogen on phosphatase activity of the isolate}

The phosphatase activity of the test isolate varied greatly with respect to carbon source used (Fig. 6).It was observed that the isolate showed optimum solubilizing activity at $3 \%$ sucrose in the medium followed by fructose $3 \%$ and dextrose $2 \%$ at $29^{\circ} \mathrm{C}$ after 6 days of incubation. In comparison to other organic sources, the isolate showed better growth at $3 \%$ starch in the medium. 


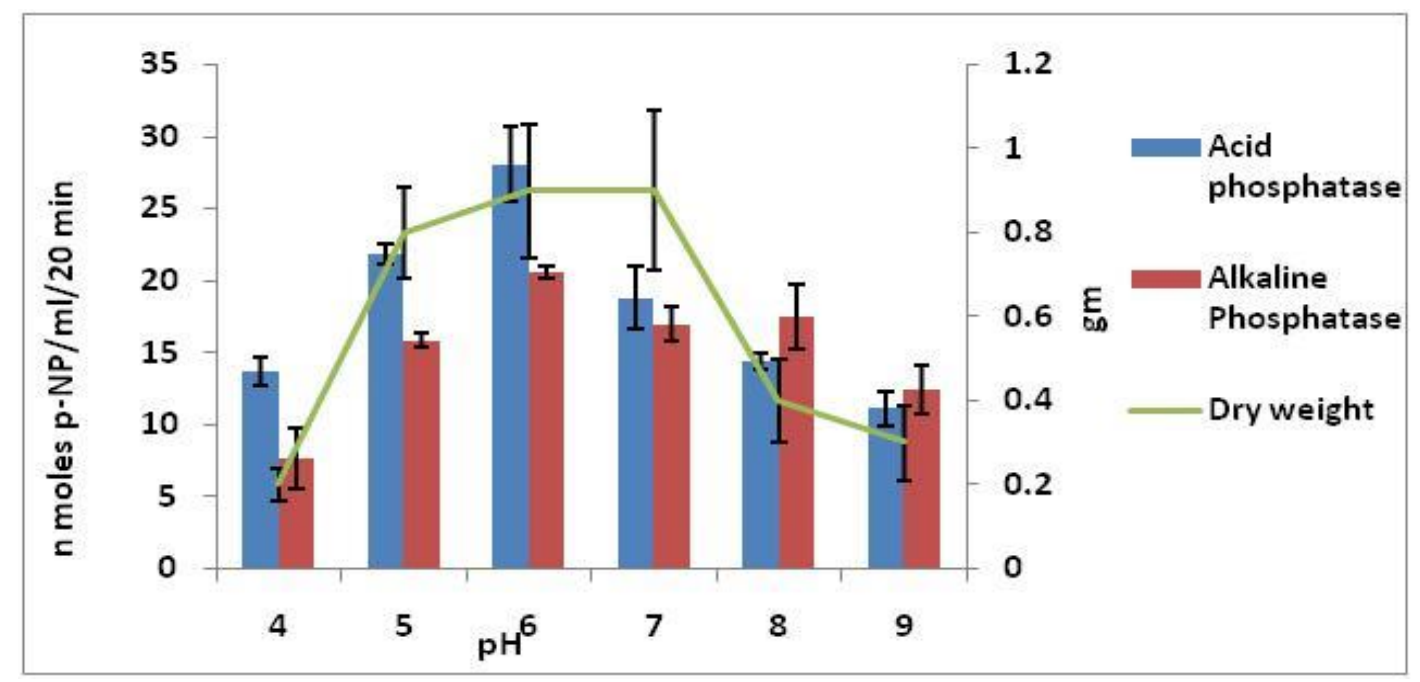

Fig. 5 - Effect of pH on phosphatase production of the fungi.

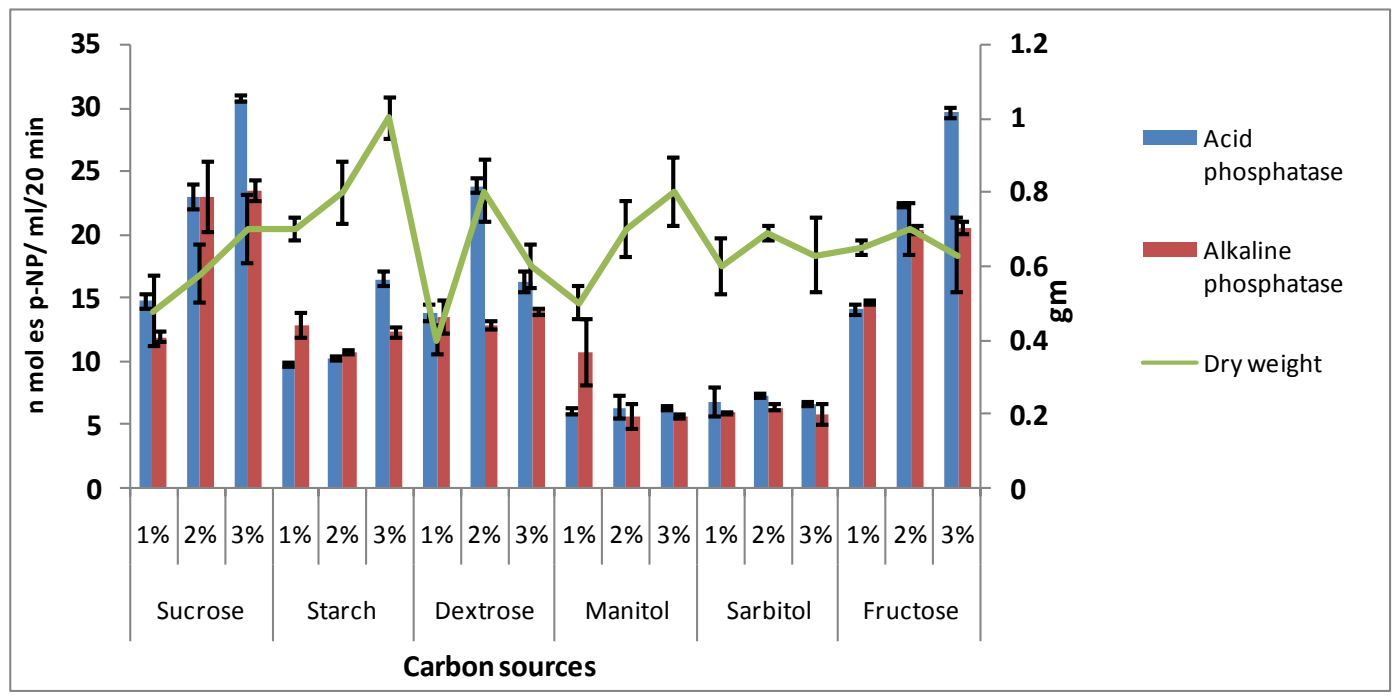

Fig. 6 - Effect of Carbon sources on phosphatase production of the isolate

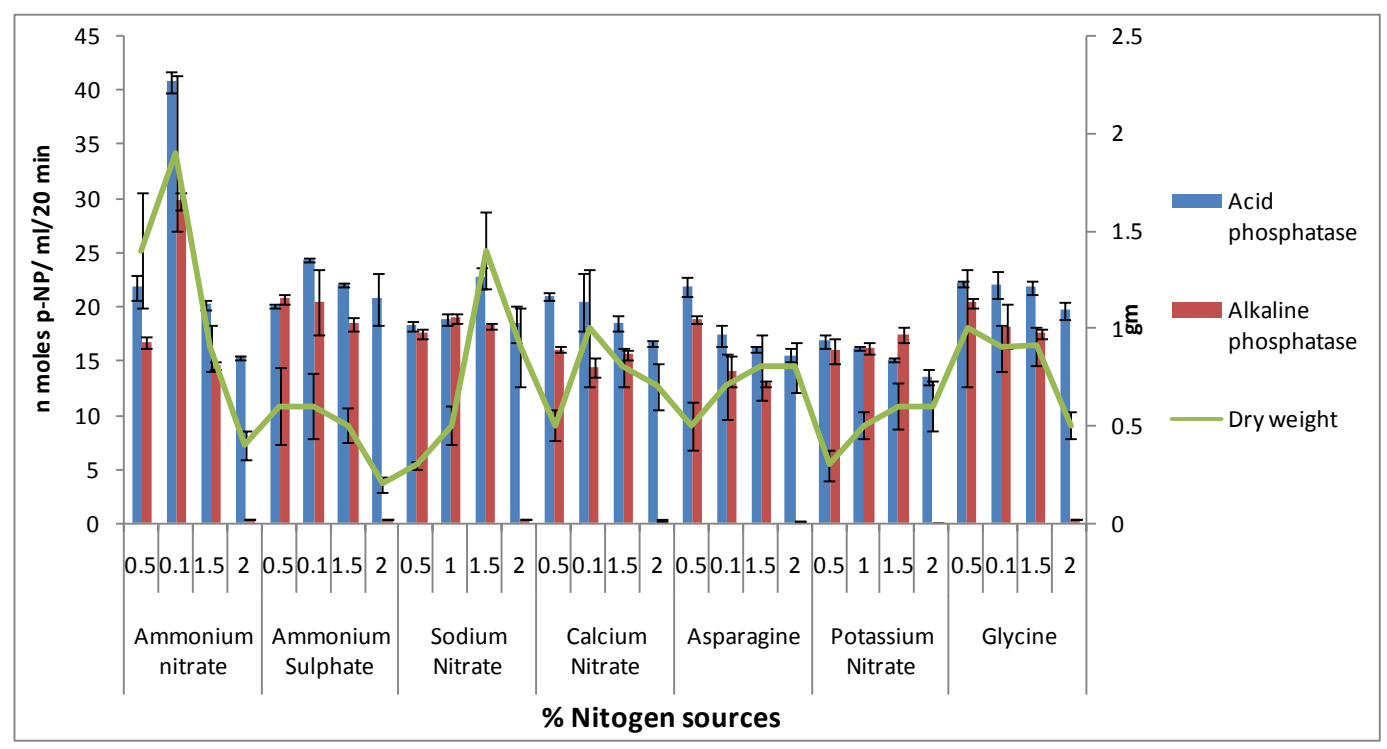

Fig. 7 - Effect of Nitrogen sources on phosphatase production 
While different Nitrogen sources were used to study their effect on phosphatase activity, it was observed that, $40.7 \pm 0.95$ and $29.77 \pm 0.79 \mathrm{n} \mathrm{mol} \mathrm{p-nitrophenol} / \mathrm{ml} / 20 \mathrm{~min}$ of acid and alkaline phosphatase respectively were released into the medium in presence of ammonium nitrate $(0.1 \%)$ in the medium (Fig. 7).

\section{Selection of carrier material for preparation of inoculum}

Fungi are heterotrophs, therefore, in this investigation we made an attempt to find out the suitable substrate (organic manure) for preparation of inoculum. Four different organic manures (Mustard cake, Groundnut cake, Neem cake and Colococia extract) were used for this study(Fig. 8). It was observed that the tri-calcium phosphate solubilization was maximum in presence of $3.1 \%$ of Mustard cake $(45.77 \pm 8.4$ and $12.58 \pm 2.17 \mathrm{n} \mathrm{mol} \mathrm{p-nitrophenol} / \mathrm{ml} / 20 \mathrm{~min}$ of acid and alkaline phosphatase respectively) with maximum growth of the isolate $(0.94 \pm 0.12 \mathrm{~g}$ of dry weight). Therefore, mustard cake was selected as the carrier material for preparation of inoculants.

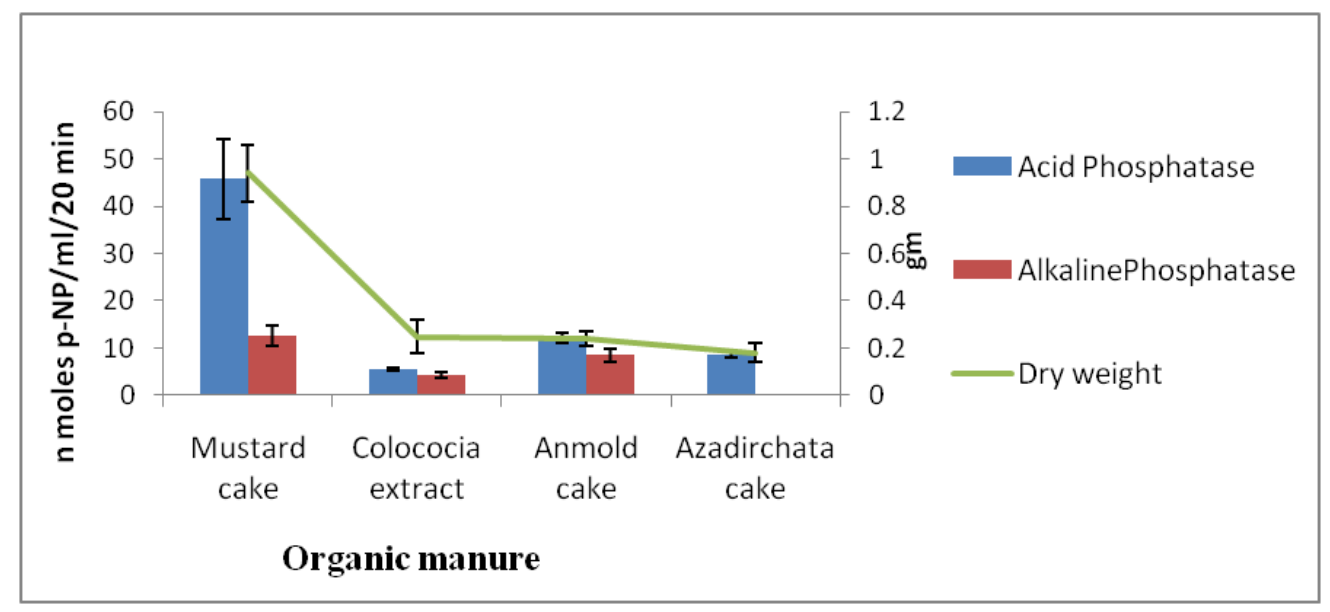

Fig. 8 - Effect of organic manure on phosphatase production

\section{Test for viability of the isolate}

From the previous experiment, Mustard cake was selected to prepare the carrier material along with the soil. Soil mixture with different concentrations of Mustard cake $(10 \%, 20 \%, 40 \%$ and $80 \%)$ was prepared. The viability of the isolate was studied at different time interval $(4,8,12$, 16, 45, 90 and 180 days) by spread plate methods and expressed CFU/gm of carrying materials. It was found that Aspergillus species population increased with increase of the concentration of Mustrad cake (Table 1) up to 16 days, later, it was observed that fungal population drastically decreased at $20-80 \%$ mustard cake after 16 days of incubation. However, the population was maintained for a longer period at $10 \%$ of concentration of mustard cake. Therefore, it is suggestive that, $10 \%$ mustard cake in the soil could be used as substratum for preparation of inoculants for the isolate.

Table 1 Viability of A. awamori in soil supplemented with mustard cake.

\begin{tabular}{|c|c|c|c|c|c|c|c|}
\hline \multirow{2}{*}{$\begin{array}{l}\% \text { of Mustard } \\
\text { cake }\end{array}$} & \multicolumn{7}{|c|}{ CFU/gm of soil vs incubation period } \\
\hline & $4 \mathrm{~d}$ & $8 \mathrm{~d}$ & $12 \mathrm{~d}$ & $16 \mathrm{~d}$ & $45 \mathrm{~d}$ & $90 \mathrm{~d}$ & $180 \mathrm{~d}$ \\
\hline Control* & $4.0 \times 10^{5}$ & $9.0 \times 10^{5}$ & $8.8 \times 10^{5}$ & $9.8 \times 10^{5}$ & $3.7 \times 10^{5}$ & $2.68 \times 10^{5}$ & $8.0 \times 10^{4}$ \\
\hline $10 \%$ & $9.0 \times 10^{5}$ & $5.0 \times 10^{6}$ & $5.8 \times 10^{6}$ & $9.2 \times 10^{6}$ & $3 \times 10^{5}$ & $2.79 \times 10^{5}$ & $2.5 \times 10^{5}$ \\
\hline $20 \%$ & $2.4 \times 10^{6}$ & $5.2 \times 10^{6}$ & $5.3 \times 10^{6}$ & $5.5 \times 10^{6}$ & - & - & - \\
\hline $40 \%$ & $5 \times 10^{6}$ & $3.2 \times 10^{7}$ & $4.4 \times 10^{7}$ & $4.6 \times 10^{7}$ & - & - & - \\
\hline $80 \%$ & $2.6 \times 10^{8}$ & $3.8 \times 10^{8}$ & $4.1 \times 10^{8}$ & $3.9 \times 10^{8}$ & - & - & - \\
\hline
\end{tabular}

*soil without mustard cake; - no. visible colonies were observed on subculture 


\section{Discussion}

In this investigation, an attempt was made to understand the effect of incubation period, incubation temperature, $\mathrm{pH}$, carbon and nitrogen sources on phosphate solubilising activity of the isolate A. awamori isolated from SBR soil. Recently, many workers reported that the Aspergillus awamori a soil fungus is of industrial and agricultural importance (Lemos et al. 2001, Kanauchi 2012, Negi \& Banerjii 2012) as observed during our study. It was observed that, the production of extracellular phosphatase enzyme was raised with increase of the incubation time up to six days (144 hrs).But, the growth of the isolate was static, after five days of incubation is indicative of optimum enzyme production in static phase, corroborates with the fact that enzyme production was maximum at static condition due to maximum metabolism of microbial cells (Qureshi et al. 2010, Lakeswari 2012). In a study, Lata et al. (2013) observed that phytase yield by Aspergillus heteromorphus MTCC 10685 decreased on prolonged incubation, as observed in our investigation, could be attributable to the reduced nutrient level of medium or autolysis of the mycelium .

We observed phosphatase production by the isolate (A. awamori) in a wide range of ( $\mathrm{pH} 4-$ 10) though, maximum phosphatase activity was reported at $\mathrm{pH}$ 6. Our findings are in agreement with Oyeleke \& Oduwole (2009) and Daniel et al. (2010) who stated that most microbial enzymes function between a pH range of 6 and 8. Kim et al. (1999) and Tahir et al. (2010) also found maximum phytase activity from Aspergillus sp. 5990 and Aspergillus niger St-6 respectively at $\mathrm{pH}$ 6.0. Further, the retention of phosphatase activity by A. awamori at a wide range of $\mathrm{pH}$ is suggestive of their potential applications as biofertilizers, for both in acidic and alkaline soils. At all the stages, the isolate produced more acidic phosphatase in comparison to alkaline phosphatase. Jena \& Rath (2013) reported that decrease of the $\mathrm{pH}$ in the growth medium was due to the production of different titrable acid \& could be attributable to the acidic phosphatase activity by the species as observed here. Further, it could be due to production of different organic acids in the medium, as organic acids play a key role to solubilising both organic and inorganic insoluble phosphates (Kpomblekou \& Tabatabai 1994, Hilda \& Fraga 2000, Deubel et al. 2000, Hinsinger 2001, Stevenson 2005, Khan et al. 2007, Henri et al. 2008).

Phosphate solubilizing efficacy of microorganisms is influenced greatly by medium composition, especially the $\mathrm{N}$ and $\mathrm{C}$ sources, and the $\mathrm{pH}$ of the medium used (Cunningham \& Kuiack 1992, Whitelaw 2000, Mehata \& Nautiyal 2001, Pradhan \& Sukla 2005). This could be due to the production of inorganic acid by proton exchange mechanism in presence of $\mathrm{NH}_{4}{ }^{+}$which causes accelerated phosphate solubilization (Sridevi et al. 2007). $\mathrm{NH}_{4}{ }^{+}$and $\mathrm{NO}_{3}{ }^{+}$are absorbed by heterotrophic organisms as a nitrogen sources. In agreement to this, we observed a higher degree of phosphatase activity when the medium was supplemented with ammonium nitrate followed by ammonium sulphate as the nitrogen source. Aspergillus niger St-6 and Aspergillus niger van Teighem produced maximum phytase with ammonium nitrate and sucrose in the medium as $\mathrm{N}$, C sources respectively (Vats \& Banerjee 2002, Tahir et al. 2010).

It is pertinent to mention that before, the use of the plant growth promoting fungi in the soil for crop improvement, the stabilization of the microbes in the soil and development of the carrier material is an important factor. During the investigation, we observed that a mixture of soil and mustard cake $(10 \%)$ could be a suitable carrier material for the isolate. Because, the isolate showed high sporulation, better activity and longer viability at $10 \%$ of mustard cake in the soil up to 6 month with population $2.5 \times 10^{5} \mathrm{CFU} / \mathrm{gm}$ carrying materials (Table 1 ).

The isolate initially was identified by microscopy through Lacto-Phenol-Cotton Blue staining in our laboratory and was confirmed by National Institute of Fungal taxonomy, New Delhi, India. Since, identification of Aspergillus sp. through morphology is a difficult task. Further, the species was identified through molecular characterization. The isolate is identified as Aspergillus awamori. The taxonomy of Aspergillus section Nigrihas been studied by many taxonomists and several schemes have been proposed (Abarca et al. 2004, Varga et al. 2006, Perrone et al. 2011). Currently, the genus Aspergillus niger is classified into eight morphologically indistinguishable complicated taxa: Aspergillus tubingensis, Aspergillus acidus, Aspergillus brasiliensis, Aspergillus costaricaensis, Aspergillus lacticoffeatus, Aspergillus piperis, and Aspergillus vadensis, 
Aspergillus awamori was first described by Nakazawa (1907). It has been treated as a synonym of A. niger (Perrone et al. 2011). Morphological and biochemical distinctiveness of fungi are universally used for their identification, but differentiation of closely related species require molecular studies to intervention for clarity in identification. The universal ribosomal DNA regions ITS and the large ribosomal subunit D1-D2 to protein encoding genes such as the $\beta$-tubulin and calmodulin gene regions have been evaluated to identify the species within aspergilli. PCR amplification with universal primers targeted to conserve regions within the rRNA complex and DNA sequencing of the internal transcribed spacer (ITS) regions, shows promise to identify a broad range of fungi to the species level (White et al. 2001, Chen et al. 2007, Balajee 2007, Shahriarnour et al. 2011, Sathiyavathi \& Parvatham 2011). In molecular characterization our strain Aspergillus is closely related to Aspergillus niger. In the tree (Fig. 2), all cryptic species of Aspergillus and our species formed cluster with maximum identity among them. Therefore, it was noted that, A. niger as the 'real' species and, for the time being, A. awamori as a 'cryptic phylogenetic species', or a phylogenetically distinct sister species of A. niger (Samson et al. 2004). Thus, during this investigation we have established that our isolate, to be Aspergillus awamori, as a cryptic phylogenetic species to Aspergillus niger with phosphate solubilising activities, to be exploited biotechnologically for their possible development as a bio fertilizer and utilization in agriculture. However, studies are essential to examine the toxicity of the strain towards plants and animals and their crop specificity (if any) before its use in agriculture.

\section{Acknowledgements}

The authors greatly acknowledge the financial support of Department of Science and Technology, Govt. Odisha. The authors duly acknowledge the help of Field Director Similipal Tiger Reserve, Baripada, permitting to carry out the research investigation inside SBR.

\section{References}

Abarca ML, Accensi F, Cano J, Cabanes FJ. 2004 - Taxonomy and significance of black Aspergilli. Antonie van Leeuwenhoek 86, 33-49.

Abe-Alla MH, Omar SA. 2001 - Survive of rizobia/Bradyrhizobia and a rock- phosphate-and their effects on nodulation and growth of faga bean and soya bean. Journal of Nutrition 24(2), 261-272.

Anderson IC, Campbell CD, Prosser JI. 2003 - Potential bias of fungal 18S rDNA and internal transcribed spacer polymerase chain reaction primers for estimating fungal biodiversity in soil. Environmental Microbiology 5, 36-47

Bakri Y, Masson M, Thonart P. 2010 - Isolation and identification of two new fungal strains for xylanase production. Applied Biochemistry and Biotechnology 162, 1626-1634

Balajee SA, Houbraken J, Verweij PE, Hong S-B, Yaghuchi T, Varga J, Samson RA.2007 Aspergillus species identification in the clinical setting. Studies in Mycology 59, 39-46

Berman T, Wynne D, Kaplan B 1990 - Phosphatases revisited: analysis of particle-associated enzyme activities in aquatic systems. Hydrobiologia 207,287-294

Chen X, Romaine CP, Tan Q, Schlagnhaufer B, Ospina-Giraldo DMD. Royse J, Huff DR 1999 PCR based genotyping of epidemic and pre epidemic Trichoderma isolates associated with green mold of Agaricus bisporus. Applied Environmental Microbiology 65, 2674-2678.

Cunningham JE, Kuiack C. 1992 - Production of citric and oxalic acids and solubilization of calcium phosphate by Pencillium bilaii. Applied Environmental Microbiology 58, 14511458.

Daimon H, Nobuta K, Ohe M, Harada J, Nakayama Y. 2006 - Tricalcium phosphate solubilising by root nodule bacteria of Sesbania cannabina and Crotalaria juncea. Plant Production Science 9,388-389.

Daniel RM, Peterson ME, Danson MJ. 2010 - The molecular basis of the effect of temperature on enzyme activity. Biochemical Journal 425(2), 353-360. 
Deubel A, Gransee A, Merbach W. 2000 - Transformation of organic rhizodepositions by rhizosphere bacteria and its influence on the availability of tertiary calcium phosphate. $\mathbf{J}$ Plant Nutrient and Soil Science 163 (4), 387-392.

Dutton VM, Evans CS. 1996 - Oxalate production by fungi: its role in pathogenicity and ecology in the soil environment. Canadian Journal of Microbiology 42,881-895.

Glass NL, Donaldson GC. 1995 - Development of primer sets designed for use with the PCR to amplify conserved genes from filamentous Ascomycetes. Applied and Environmental Microbiology 61, 1323-1330.

Henri F, Laurette NN, Annette D, John Q, Wolfgang M, Francois-Xavier M, Dieudonne N. 2008 Solubilization of inorganic phosphates and plant growth promotion by strains of Pseudomonas fluorescens isolated from acidic soils of Cameroon. African Journal of Microbial Research 2, 171-178.

Hilda R, Fraga R. 2000 - Phosphate solubilizing bacteria and their role in plant growth promotion. Biotechnology Advances 17, 319-359.

Hinsinger P. 2001 - Bioavailability of soil inorganic P in the rhizosphere as affected by root induced chemical changes: A Review of Plant Soil 237, 173-195.

Illme P, Schinner F. 1992 - Solublization of inorganic phosphate by microorganisms isolated from forest soil. Soil Biology and Biochemistry 24, 389-395.

Jena SK, Rath CC. 2013 - Optimization of culture conditions of phosphate solubilizing activity of bacterial sp. isolated from Similipal Biosphere Reserve in solid-state cultivation by response surface methodology. International Journal of Current Microbiology and Applied Science 2(5), 47-59.

Kanauchi M. 2012 - Characteristics and role of feruloyl esterase from Aspergillus awamori in Japanese spirits, 'Awamori' production Japan scientific, Health and Social Aspects of the Food Industry, Publisher In Tech. 145-162.

Khan MS, Zaidi A, Wani PA. 2007 - Role of phosphate-solubilizing microorganisms in sustainable agriculture - A reviewAgronomy for Sustain Development 27, 29-43.

Khan AA, Jilani G, Mohammad SA, Muhamma SSN, Mohamma R. 2009 - Phosphorus Solubilizing Bacteria: Occurrence, Mechanisms and their Role in Crop Production. Journal of Agricultural and Biological Science 1(1), 48-58.

Khiari L, Parent V. 2005 - Phosphorus transformations in acid light-textured soils treated with dry swine manure. Canadian Journal of Microbiology 85, 75-87.

Kim DS, Godber JS, Kim HR. 1999 - Culture conditions for a new phytase producing fungus. Biotechnology Letters 21, 1077-081.

Kpomblekou K, Tabatabai MA. 1994 - Effect of organic acids on release of phosphorus from phosphate rocks. Soil Science 158, 442-453.

Lata S, Rastogi S, Kapoor A, Imran M. 2013 - Optimization of culture conditions for the production of phytase from Aspergillus heteromorphus MTCC 10685. International Journal of Advance Biotechnology and Research 4, 224-235.

Lemos JL, Fontes MC, Pereira NJ. 2001 - Xylanase production by Aspergillus awamori in solidstate fermentation and influence of different nitrogen sources. Applied Biochemistry and Biotechnology 91-93, 681-9.

Lo’ pez L, Pozo C, Rodelas B, Calvo C, Gonzalez-Lo'pez J. 2006 - Influence of pesticides and herbicides presence on phosphatase activity and selected bacterial microbiota of a natural lake system. Ecology and Toxicology 15, 487-493.

Lakeswari N. 2012 - Optimization of environmental parameters for maximum tannase production from cashew husk. International Journal of Pharmaceutics 2, 375-379.

Mehata S, Nautiyal CS. 2001 - An efficient method for qualitative screening of pyhosphate solubilizing bacteria. Current Microbiology 43, 51-56.

Nahas E. 1996 - Factors determining rock phosphate solubilization by microorganism isolated from soil. World J Microbial Biotechnology 12, 18-23.

Nakazawa R 1907 - Onkoji fungus, Aspergillus awamori. Rept. Inst. Govt. Res. Formosa. vol. 1. 
Negi S, Banerjii R. 2000 - Amylase and protease production from A. awamori. Food Technology and Biotechnology 44, 257-261.

Nei M, Kumar S. 2000 - Molecular Evolution and Phylogenetics. Oxford University Press, New York.

O'Donnell K. 1993 - Fusarium and its near relatives Reynolds D.R, Taylor J.W In The fungal holomorph: mitotic, meiotic and pleomorphic speciation in fungal systematics Wallingford, $\mathrm{UK}: \mathrm{CAB}$ International.

Oyeleke SB, Oduwole AA. 2009 - Production of amylase by bacteria isolated from a cassava waste dumpsite in Minna, Niger State, Nigeria. African Journal of Microbiology Research 3, 143146.

Perrone G, Stea G, Epifani F, Varga J, Frisvad JC, Samson RA. 2011 - Aspergillus niger contains the cryptic phylogenetic species A. awamori. Elsevier Biology 115, 1138-1150.

Pradhan N, Sukla LB. 2005 - Solubilization of inorganic phosphate by fungi isolated from agriculture soil. African Journal of Biotechnology 5, 850-854.

Qureshi AS, Dahot MU, Panhwar SI 2010 - Biosysnthesis of Alkaline Phosphatase by Escherichia coli Efrl 13 in Submerged Fermentation. Applied Science 8, 50-56.

Samson RA, Houbraken JAMP, Kuijpers AFA, Frank JM, Frisvad JC. 2004 - New ochratoxin or sclerotium producing species in Aspergillus section Nigri. Study in Mycology 50, 45-61.

Sathiyavathi M and Parvatham R. 2011- Identification and molecular characterisation of laccase and xylanase producing fungus isolated from paper mill effluent. International Journal of Pharmaceutical and Bioscience 2(4), 54-66.

Sridevi M, Mallaiah KV, Yadav NCS. 2007 - Phosphate solubilizing by Rhizobium from Crotalaria species. Journal of Plant Science 2, 635-639.

Stevenson FJ. 2005- Cycles of Soil: Carbon, Nitrogen, Phosphorus, Sulphur, Micronutrients. John Wiley and Sons, New York.

Surange S, Wollum A G, Kumar V, Nautiyal CS. 1995 - Characterization of Rhizobium from root nodules of leguminous trees growing in alkaline soils. Canada J Microbiol 43, 891- 894.

Tahir A, Mateen B, Saeed S, Uslu H. 2010- Studies on the production of commercially important phytase from Aspergillus niger ST-6 isolated from decay ingorganic soil. Micologia Aplicada International 22, 51-57.

Tamura K, Peterson D, Peterson N, Stecher G, Nei M, Kumar S. 2011 - MEGA5: Molecular Evolutionary Genetics Analysis using Maximum Likelihood, Evolutionary Distance, and Maximum Parsimony Methods. Molecular Biology and Evolution doi: 10.1093/molbev/msr121.

Varga J, Rigo K, Kocsube S, Pal K, Toth B, Samson RA, Kozakiewicz Z. 2006 - Evolutionary relationships among economically important species of Aspergillus subgenera Aspergillus and Fumigati. In: Sharma AK, Sharma A (eds), Plant Genome: Biodiversity and Evolution 2, 285-332.

Vats P, Banerjee UC. 2002 - Studies on the production of phytase by a newly isolated strain of Aspergillus niger van Teighem obtained from rotten wood-logs. Process Biochemistry 38, 211-217.

Vazquez P, Holguin G, Puente ME, Lopez -Cortes A, Bashan Y. 2000 - Phosphate-solubilizing microorganisms associated with the rhizosphere of mangroves in a semiarid coastal lagoon. Biology and Fertility of Soil 30, 460-468.

White NA, Dehal PK, Duncan JM, Williams NA, Gartland JS, Palfreyman JW, Cooke DEL. 2001 Molecular analysis of intraspecific variation between building and wild isolates of Serpulalacrymans and their relatedness to S. himantioides. Mycological Research 105, 447452 .

Whitelaw MA. 2000 - Growth promotion of plants inoculated with phosphate solubilizing fungi. Advance Agronomy 69, 99-151. 